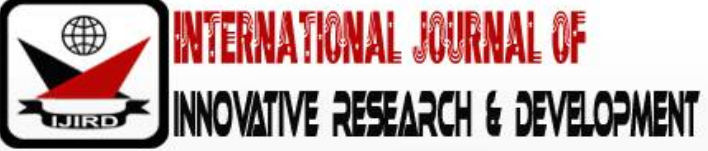

ISSN 2278 - 0211 (Online)

\section{Contribution of Intellectual Capital to Competitive Intelligence}

\author{
Inès Jedidi \\ Permanent Assistant-Resercher, Higher School of Economic and Commercial Sciences, \\ University of Tunis, Tunisia \\ Fatma Chichti \\ Assistant Professor, Higher Institute of Accounting and Business Administration, \\ University of Manouba, Tunisia
}

\begin{abstract}
:
Some authors found that competitive intelligence (CI) can be generated by the intellectual capital (IC). Based on the resources approach, we suggest digging in this reasoning through studying the contribution of the different forms of the intellectual capital (IC), namely the human capital (HC), the structural capital (SC) and the relational capital (RC), to the success of the competitive intelligence practices in the Tunisian companies.

Our empirical study has been conducted with 127 middle managers working in companies operating in the telecommunications sector in Tunisia. We have revealed that the human capital (HC) is the most linked to competitive intelligence (CI), followed by the relational capital (RC), and that there is no significant link between the structural capital (SC) and the competitive intelligence (CI).
\end{abstract}

Keywords: Intellectual capital, human capital, structural capital, relational capital, information, competition

\section{Introduction}

The strong competition and the looking for a sustainable competitive advantage have made information a critical resource for the company. Collecting and analyzing information about competitors helps to understand their strategies in order to get ahead of them and gain in competitiveness. This implies new ways of creating value for customers, through the development of new products, the extension of the existing product ranges, the modification of existing products, etc. Therefore, competitive intelligence (CI) seems to be the appropriate practice since it is based on a better understanding of the sector and competition. It allows the decision makers to take a step ahead of their competitors through identifying the opportunities and avoiding the threats, reducing uncertainty in decision-making and thus achieving better results. Some authors found that the competitive intelligence (CI) can be generated by the intellectual capital (IC) (Bontis, 2002). Based on the resources approach, we suggest studying the contribution of the different forms of intellectual capital (IC), namely the human capital (HC), the structural capital (SC) and the relational capital (RC), to the success of the competitive intelligence practices in the Tunisian companies.

This research is structured as follows. The first part is devoted to the literature review from which we have formulated the hypotheses and developed the conceptual model. The second part highlights the methodology, the presentation and the discussion of the empirical results. In the last part, we conclude through presenting the limits and the future research prospects.

\section{The Intellectual Capital and the Competitive Intelligence: Definitions}

The intellectual capital is the term used to describe the intangible assets that do not physically exist however they add value and enable the company to operate (Angelini et al, 2019). It is similarly considered as knowledge that can be converted into profit (Joshi et al., 2011). In this research, we conceptualize IC as a triptych integrating HC, SC and RC in the line of Cabrita and Bontis (2008). HC is defined as the whole of the intangible resources owned by the employees of a company (skills, leadership, attitude, creativity, etc.). Some authors found that the intangible wealth resides in the HC. It's the primary source of the IC generation. Moreover, the HC is considered to be the main source of innovation since the employees suggest innovative ideas through experience and learning and develop a competitive advantage (Allameh, 2018). SC is considered a fundamental component of IC since it provides the framework and modes of knowledge transfer (Harris, 2000). It is defined as all the intangible resources not incorporated in the company employees and which includes corporate culture, organizational learning, information system, information and communication technologies, etc. (Siana, 2010). The RC characterizes the formal and the informal relationships and knowledge exchange between the company and its external stakeholders such as clients, suppliers, institutions, etc. (Kamukama, 2011). 
The competitive intelligence is a relatively new management concept developed from the main idea of Porter's five competitive forces (Nenzhele and Pellissier, 2013). It is the process of collecting, analyzing and sharing information about competitors and competitive environment in general (market evolution, strengths and weaknesses, positioning, etc.), and being competitive through choosing the appropriate strategic decisions (Bontis, 2002).

\section{The Impact of the Intellectual Capital on Competitive Intelligence}

\subsection{Contribution of $\mathrm{HC}$ to $\mathrm{CI}$}

Each employee must be able to add value in terms of information. In fact, the job of analyst has become indispensable for any company. This specialist in the collection and the decryption of information must have qualities such as intuition, discernment and anticipation to optimize decision-making. Some authors consider that the HC allows the successful exploitation of human resources ideas (Ginesti et al, 2018). The Knowledge gained from learning and experience is reflected in ideas and can be a source of competitive advantage. The analyst integrates relevant information into decision-making at the right time. Thus, we hypothesize that:

- $\mathrm{H} 1: \mathrm{HC}$ is positively related to $\mathrm{CI}$.

\subsection{Contribution of SC to CI}

SC provides the framework and the means of knowledge transfer and therefore relies on information gathering. The companies set up systems to collect relevant competition information. This information will be analyzed for decision-making purposes (Shaari et al., 2011). Some authors consider that CI is part of the existing non-human knowledge stock in the company and thus it is a component of SC (Maheran and Khairu, 2009). We deduce this hypothesis:

- $\quad \mathrm{H} 2$ : SC is positively related to $\mathrm{CI}$

\subsection{Contribution of RC to CI}

The relational capital refers to the knowledge exchange of the company with its stakeholders. The information exchanged concerns the customers, the channels, the suppliers, the competitors, etc. Competitive intelligence practices focus on information about competitors (products and services, strategies, quality, prices, customer satisfaction, communication, product development processes, etc.). The sources of such information may be formal (published information) or informal (social networks, discussion groups, and conferences). Some authors found that competitive intelligence is a process of gathering and sharing information about competitors and can therefore be a component of the relationship capital (Stewart, 1997). Thus, we hypothesize that:

- $\mathrm{H} 3$ : $\mathrm{RC}$ is positively related to IC

\section{The Research Method}

\subsection{Data Collection and Sample}

In order to test our research model (Figure 1), we have conducted a quantitative study with 127 middle managers working in companies operating in the telecommunications sector in Tunisia, which is a highly competitive sector. We have chosen the middle managers because of the importance of their roles in information sharing and in upward and downward communication. We have selected a convenience sample. Our questionnaire has been pre-tested using eight middle managers to improve the original version. We have administered it to 300 middle managers and we got a response rate of $43 \%$.

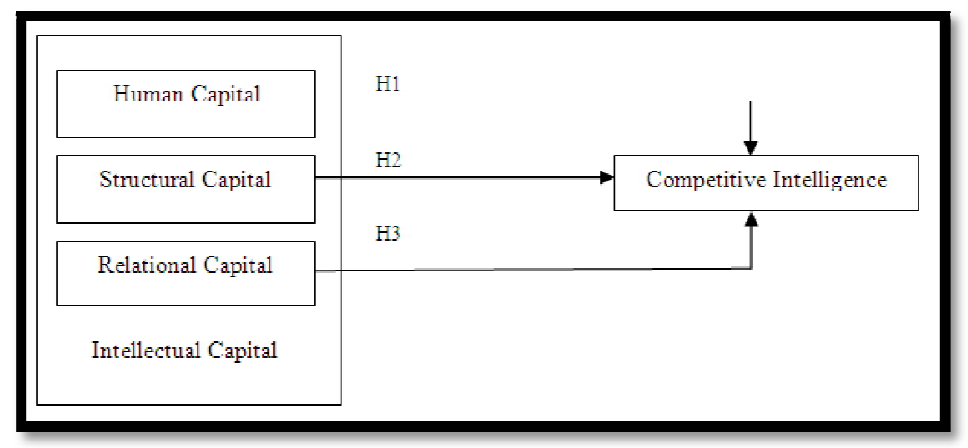

Figure 1: Conceptual Model

\subsection{Measurement}

In order to measure IC, we have chosen the scale developed by Ramezan (2011) which consists of three dimensions: HC (12 items), SC (12 items) and RC (12 items). CI is measured by the Saayman and al (2008) measurement scale (6 items) describing the process of this practice: planning, collection, analysis, communication, structure and organizational culture. 
Before testing the hypotheses, we will check the psychometric quality of the measuring instruments through using the SPSS software to perform the principal component analysis (PCA) and then we will check the internal consistency by calculating Cronbach's alpha. We have examined the factorization conditions of the two variables: The KMO index (Kaiser, Meyer and Olkin) shows values above 0.5 and the Bartlett's test is significant. We have also carried out a second PCA with Varimax rotation. We have confirmed the multi-dimensional nature of the intellectual capital and the uni-dimensionality of the competitive intelligence. The factor loading of all the items exceed the threshold of 0.5 and the reliability is verified since the values of Cronbach's alpha declare values above the critical threshold of 0.6. (Table 1)

\begin{tabular}{|c|c|c|c|c|}
\hline Constructs & Dimensions & Factor loading & Cronbach's Alpha & KMO \\
\hline \multirow{3}{*}{ Intellectual capital } & Human capital & $0.749-0.909$ & 0.946 & \multirow{2}{*}{0.891} \\
\cline { 2 - 4 } & Structural capital & $0.721-0.817$ & 0.889 & \\
\cline { 2 - 4 } & Relational capital & $0.747-0.860$ & 0.883 & \multirow{2}{*}{0.827} \\
\hline Competitive intelligence & - & $0.727-0.829$ & 0.927 & \\
& & &
\end{tabular}

Table 1: Results of the Exploratory Phase

Subsequently, we have conducted a confirmatory factor analysis by using LISREL 9.2 software in order to verify the reliability and validity of the measuring instruments. The adjustment indices of the measurement models are satisfactory (Table 2). The reliability has been verified with a Jöreskog's rho above 0.6 . The convergent validity is similarly confirmed since the convergent validity rho values are greater than 0.5 and significant at the $1 \%$ threshold, following the approach of Fornell and Larcker (1981) (Table3). This approach has also been used to check the discriminant validity of the IC (Table 4). Indeed, discriminant validity was analyzed by ensuring that the average extracted variance (AVE) of each construct is superior to the square correlations between constructs. Since the factorial structure of CI is one-dimensional, we cannot appreciate its discriminant validity.

\begin{tabular}{|c|c|c|}
\hline & $\begin{array}{c}\text { Intellectual } \\
\text { Capital }\end{array}$ & Competitive Intelligence \\
\hline RMSEA & 0.029 & 0.095 \\
\hline NFI & 0.95 & 0.91 \\
\hline CFI & 1.00 & 0.99 \\
\hline GFI & 0.91 & 0.94 \\
\hline
\end{tabular}

Table 2: Measurement Model of the Adjustment Indices

\begin{tabular}{|c|c|c|}
\hline & Jöreskog's rho & convergent validity's rho \\
\hline Human capital & 0.947 & 0.72 \\
\hline Structural capital & 0.890 & 0.58 \\
\hline Relational capital & 0.886 & 0.53 \\
\hline $\begin{array}{c}\text { Competitive } \\
\text { intelligence }\end{array}$ & 0.89 & 0.62 \\
\hline
\end{tabular}

Table 3: Convergent Validity and Reliability

\begin{tabular}{|c|c|c|c|}
\hline & Human Capital & Structural Capital & $\begin{array}{c}\text { Relational } \\
\text { Capital }\end{array}$ \\
\hline $\begin{array}{c}\text { Convergent } \\
\text { validity rho }\end{array}$ & 0.72 & 0.58 & 0.53 \\
\hline $\begin{array}{c}\text { Human } \\
\text { Capital }\end{array}$ & 1 & 1 & \\
\hline $\begin{array}{c}\text { Structural } \\
\text { Capital }\end{array}$ & 0.0004 & 0.0144 & 1 \\
\hline $\begin{array}{c}\text { Relational } \\
\text { Capital }\end{array}$ & 0.04 & 0.01 \\
\hline
\end{tabular}

Table 4: Discriminant Validity of the Intellectual Capital

\subsection{Testing the Hypotheses}

In this stage, we will verify the nature and significance of the relationships between the latent variables by the software LISREL 9.2 through using the regression coefficients and the Student's t-test which must be greater than 1.96 in absolute terms (Roussel et al, 2002). A positive and statistically significant relationship has been established between HC and $\mathrm{CI}$, which allows the validation of H1. A positive and statistically non-significant relationship was determined between SC and CI. H2 is therefore rejected. The relationship between RC and CI is positive and statistically significant. H3 is therefore confirmed (Table 5) 


\begin{tabular}{|c|c|c|}
\hline Structural Links & Regression Coefficient & Student's t test \\
\hline Human capital - Competitive intelligence & 0.49 & $|12.27|>1.96$ \\
\hline Structural capital - Competitive intelligence & 0.07 & $|1.07|<1.96$ \\
\hline Relational capita l - Competitive intelligence & 0.09 & $|5.29|>1.96$ \\
\hline
\end{tabular}

Table 5: Results of the Structural Model

\section{Discussion}

The empirical verification of the hypotheses has allowed us to partially confirm the existence of a positive impact of intellectual capital on competitive intelligence. Indeed, CI benefits from the intangible resources (Liebowitz, 2006).

First, we have proposed a hypothesis stating that HC is positively related to CI. This hypothesis has been confirmed. In addition, HC is the capital which has the greatest impact on CI. In fact, a manager should be able to collect, analyze, interpret and share information in order to facilitate optimal decision-making. He must therefore be able to identify the most relevant sources of information and have the ability to discern between the confidential information and the general information. The disclosure of confidential information would be detrimental to the business. General information is open to all staff. The employees of the different directorates and middle managers provide information to the analysts in order to analyze the current strategies of the competitors and anticipate potential strategies. Indeed, through detecting the competitors' strengths and strategies, the company can determine its areas for improvement and the products to be developed or to be avoided. The Competitive Intelligence Committee is therefore a tool to help decision-making. Similarly, the companies operating in the telecommunications sector perform benchmarking practice. These results are similar to those of Aramide and Adebisi (2018).

Second, our theoretical analysis led to a hypothesis stating that there was a positive relationship between SC and CI. This hypothesis has been rejected. This result seems to contradict the previous research claiming that SC is linked to CI through knowledge sharing and transfer (Hakkak et al, 2015). Indeed, SC is based on gathering information, for example the competitive intelligence system has the role of collecting and analyzing information about competitors in order to assist in decision-making (Erickson, 2000). It seems that the practice of CI in the studied companies is not entirely devoted due to a lack of relevant information sharing and data exchange. Some directors prefer to protect information because its possession confers some power, especially, since it is not easy to have it. This can reflect a "top-down" management style in which decisions are centralized at the top-level managers.

Third, we have hypothesized that the RC is positively related to CI. Indeed, the RC of the studied companies allows them to have information about their competitors (strengths, weaknesses, strategies, etc.) from customers, common suppliers, media, former employees of the competitor, patenting process, websites, databases, etc. The relatively small impact of RC on CI may be explained by the difficulty of obtaining relevant information about competitors, especially since its main source is informal. This low impact could have consequences and could justify the lack of relationship between SC and CI since SC is dependent on RC (Bontis et al, 2000).

\section{Conclusion}

Our results provide empirical evidence that enriches the literature on CI practice. In fact, despite its importance, especially that the environment is highly competitive, there are few studies focusing on how CI practice works in the Tunisian companies. Based on the resource approach, the objective of this research is to examine the relationship between IC and CI. From this perspective, we have found that $\mathrm{HC}$ is the most related capital to $\mathrm{CI}$, followed by the RC. Indeed, the employees collect and analyze information about the competitors in order to imitate, or to advance, to seize the opportunities, or to ovoid threats. The information is obtained from the company's knowledge exchange with its stakeholders.

However, our study found no link between SC and CI. This result is surprising given that CI is considered to be a SC system for competition analysis. Indeed, there is a resistance to sharing information in the companies operating in the telecommunications sector. This trend towards information retention may be explained by the difficulty of obtaining it, especially since the most important information is informal. The new technologies, the social networking and the collaborative tools are likely to enhance corporate transparency and promote the flow and exchange of information. The employees should have more flexibility, they should use platforms that aggregate access to resources, and transfer knowledge in order to optimize decision-making.

This research has a number of limitations. First, the sample of convenience does not allow the generalization of the research results. Second, we have conducted a quantitative study that not allows understanding how concretely each type of IC affects CI. Future researchers may conduct a mixed approach by combining between qualitative and quantitative studies to better examine the relationships among the variables and to better understand the impact of CI on the company's competitiveness. We similarly suggest studying the mediating role of competitive intelligence in the relationship between the intellectual capital and the competitive advantage. Indeed, the competitive intelligence can transform the intellectual capital into competitive capital. 


\section{References}

i. Allameh, S-M. (2018). Antecedents and consequences of intellectual capital. Journal of Intellectual Capital, 19(2), 858-874

ii. Angelini, M-S., Gennaro, A., \& Labella, S. (2019). Disclosure on Intellectual Capital in the Age of Industry 4.0. Management Studies, 7 (1), 1-14,

iii. Aramide, O-A., \& Adebisi, S-K. (2018), Information Use, Competitive Intelligence and Organizational Performance: Human Information Behaviour Perspective. Journal of Business and Management, 20 (5), 39-45.

iv. Bontis, N., Kew, W-C-C., \& Richardson, S. (2000). Intellectual capital and business performance in Malaysian industries. Journal of Intellectual Capital, 1(1), 85-100.

v. Bontis, N. (2002). World Congress on Intellectual Capital Readings. KMCI Butterworth-Heinemann Press: Boston, MA

vi. Cabrita, M- R., \& Bontis, N. (2008). Intellectual capital and business performance in the Portuguese banking industry. International Journal Technology Management, 43 (1), 212-237.

vii. Erickson, G-S., \& Rothberg, H-N. (2000). Intellectual capital and competitiveness: guidelines for policy. Competitiveness Review: An International Business Journal, 10(2), 192-198.

viii. Fornell, C., \& Larcker, D-F. (1981). Evaluating structural equation models with unobservable variables and measurement error. Journal of Marketing Research,18, 39-50.

ix. Ginesti, G., Caldarelli, A. \& Zampella, A. (2018). Exploring the impact of intellectual capital on company reputation and performance. Journal of Intellectual Capital, 19(5), 915-934.

x. Hakkak, M; Vahdati, H., \& Jahanbakhsh, N. (2015). The effect of intellectual capital on competitive intelligence through the sharing and transfer of knowledge. International Journal of Applied Business and Economic Research, 13(8), 6593-6602.

xi. Harris, L. (2000). A Theory of Intellectual Capital. Advances in Developing Human Resources, 2, 22-37.

xii. Joshi, M., Ubha, D.S., \& Sidhu, J. (2011). Intellectual Capital Disclosures in India: A Case Study of Information Technology Sector. Global Business Review, 12, (1), 37-49.

xiii. Kamukama, N., Ahiauzu, A., \& Ntayi, J-M. (2011). Competitive advantage: mediator of intellectual capital and performance. Journal of Intellectual Capital, 12 (1), 152-164.

xiv. Liebowitz, J. (2006). Strategic intelligence: Business intelligence, competitive intelligence, and knowledge management. Boca Raton, FL: Auerbach Publications. Limpanitgul

xv. Maheran, N-M.\& Khairu, K-I. (2009). Intellectual capital efficiency and firm's performance: study of Malaysian financial sectors. International journal of economics and finance, 1(2), 206-212.

xvi. Nenzhelele, T., \& Pellissier, R. (2013). Towards a universal definition of competitive intelligence. South African Journal of Information Management, 15(2),1-7.

xvii. Ramezan, M. (2011). Intellectual capital and organizational organic structure in knowledge society: How are these concepts related? International Journal of Information Management, 31, 88-95.

xviii. Roussel, P., Durrieu, F., Campoy, E., \& El Akremi, A. (2002). Méthodes d'Equations Structurelles : Recherche et Applications en Gestion : Economica.

xix. Saayman, A., Pienaar, J., Pelsmackr, P., Viviers, W., Cuyvers, L., Muller, M-L., Jegers, M. (2008). Aslib Competitive intelligence : construct exploration, validation and equivalence Proceedings. New Information Perspectives, 60(4), 383-411.

xx. Shaari, J-A., Khalique, M., \& Isa, A-B. (2011). Ranking of Public and Domestic Private Sector Commercial Banks in Pakistan on the Basis of the Intellectual Capital Performance KASBIT Business Journal, 4, 61-68.

xxi. Siana, H. (2010). Statistical analysis on the intellectual capital statement. Journal of Intellectual Capital, 11(1), 61-73.

xxii. Stewart, T-A. (1997). Intellectual capital. The new wealth of nations: Crown Business. 